DOSSIÊ MULHERES, GÊNERO, SERTANIDADES

DOI 10.22478/ufpb.2317-6725.2019v24n41.49590

\title{
Lugares de escuta e de acolhimento nas pesquisas sobre sertanidades
}

\author{
Listening and welcoming spaces in the research on sertanidades \\ Ana Maria Veiga \\ https://orcid.org/0000-0003-0446-1472 \\ Universidade Federal da Paraíba \\ Vânia Nara Pereira Vasconcelos \\ https://orcid.org/0000-0002-8187-2614 \\ Universidade do Estado da Bahia
}

\begin{abstract}
Resumo: Este texto se propõe a mapear o surgimento de um campo de estudos que vem se consolidando a partir de pesquisas individuais e pontuais que tratam das relações entre gênero, história das mulheres e sertanidades. Em 2018 foi criado o grupo de pesquisa ProjetAH, reunindo professoras e estudantes de universidades diversas que atuam no campo acadêmico e/ou em movimentos relacionados com a temática. $O$ grupo passou a se constituir como um "lugar de escuta" de histórias e da produção de memórias de mulheres e da população LGBTQI+. O campo de estudos sobre gênero, mulheres e sertanidades entra em diálogo com as teorias pós/decoloniais, assim como incorpora o conceito de interseccionalidades, dando visibilidade a sujeitas/os ausentes de uma historiografia que tradicionalmente não considera sujeitos em situação de margem, que vivem em territorialidades sertanejas.
\end{abstract}

Palavras-chave: Mulheres. Gênero. Sertanidades. Territorialidades.

Abstract: This text proposes to map the emergence of a field of study that has been consolidating itself out of specific, individual research dealing with the relation between gender, women's history, and sertanidades (as practices and representations related to the sertão). In 2018 the ProjetAH research group was created, bringing together professors and students from different universities who in some way work in the academic field and/or in movements related to the theme. The group came to be a "listening space" for narratives and for the production of memories of women and the LGBTQI+ population. The field of study of gender, women and sertanidades dialogues with post/decolonial theories and incorporates the concept of intersectionalities, rendering visible subjects historically absent from a historiography that did not consider marginalized individuals living in semi-arid territorialities.

Keywords: Women. Gender. Sertanidades. Territorialities.

Pretendemos, com este breve balanço apresentado na forma de ensaio, dar conta de apresentar um campo que começa a se consolidar, agregando pesquisas e trabalhos acadêmicos em torno da temática gênero e sertões. Mapeado inicialmente por esforços isolados e pontuais, o campo passa pela formação de uma rede que começa a atuar em conjunto, ganhando aos poucos espaço e reconhecimento, abrindo territórios intelectuais próprios. Entre competências científicas e afetos, as trocas e os

Esta obra está licenciada sob uma Creative Commons - Atribuição 4.0 Internacional 
compartilhamentos estão na base dessa proposta de pensar sertanidades com perspectivas outras, que buscam ir além da leitura e interpretação dos clássicos e da visibilidade dos "cabra-machos" e coronéis. Os sertões que aparecem são narrados na ótica das mulheres, das práticas sociais invisíveis, dos sujeitos antes considerados impossíveis, deslocados, seja nos termos de existências e vivências socialmente localizadas, mas, mais ainda, na visibilidade de suas histórias, trajetórias e memórias.

Se buscarmos nos embrenhar nos sertões da teoria, iremos perceber a necessidade da aproximação com outras noções que demarquem uma ausência ou um afastamento de uma historiografia preponderante, de mainstream, protagonizada por universidades localizadas em eixos historicamente privilegiados, como as regiões sudeste e sul do Brasil.

Olhar para os sertões, e para as mulheres sertanejas, sob as lentes da história, implica em acionar outras ferramentas conceituais interdisciplinares das quais dificilmente poderíamos escapar nos dias atuais. A percepção de uma "colonialidede do poder" (conceito do peruano Aníbal Quijano), que permeia as relações econômicas e socioculturais, entre elas as acadêmicas, deixa claro que estamos lidando com uma situação de periferia, ao trabalharmos com (não) sujeitos históricos e suas experiências intersectadas por outros fatores de exclusão, como raça, etnia, situação econômica e localização, agregados sob o conceito de interseccionalidade (Crenshaw, 2002). Para María Lugones (2008; 2014), é ineficiente tratar do conceito de colonialidade sem situar a matriz do gênero como eixo ao redor do qual a colonialidade se estabelece, em sua faceta interseccional.

Lélia Gonzalez já apresentava essa noção das múltiplas opressões no final dos anos 1970, transformando-a em reflexões intelectuais. Suas propostas de pensar nos termos de uma amefricanidade, destacando mulheres negras e indígenas (incluímos aqui as sertanejas), entendendo sua fala em termos próprios como um sincretismo que resulta no "pretuguês" como língua dos pretos, que não traziam as mesmas referências linguísticas do colonizador, afetam diretamente nosso campo de estudos, quando buscamos entender, mais que traduzir dialetos e expressões próprias das territorialidades sertanejas.

Em termos de América Latina, a colombiana Mara Viveros Vigoya argumenta que os conhecimentos dos povos colonizados foram ocultados na experiência marcada pela racialização, seus traços foram sendo apagados sutilmente sob os subterfúgios dos conceitos de mestiçagem e de democracia racial. Viveros Vigoya entende que as histórias das mulheres latino-americanas devem ser analisadas sob um prisma que integre classismo, sexismo e racismo, além da perspectiva decolonial. E quando se refere à situação dessas mulheres e suas especificidades locais, ela recupera a teoria de Lélia Gonzalez. Desafiadora, a brasileira propunha que se assumisse uma linguagem mista e política, que seria a forma de locução das brasileiras pobres em confronto com as elites. As línguas africanas, traficadas junto com os escravos e escravas para o Brasil, eram vistas como distorções da língua culta, tal como acontecia em regiões de colonização espanhola. Como exemplo do já mencionado pretuguês, aparece a palavra Flamengo, cujo som se modificava no para Framengo, já que o "l" era inexistente na linguagem e na fonética das regiões de onde vinha boa parte das pessoas escravizadas.

Para Viveros Vigoya, o branqueamento está no subtexto do conceito de mestiçagem, entendido como uma chave histórica para se pensar em mesclas abjetas. Concordamos com ela quando afirma a necessidade de um projeto de renovação epistêmica, que dê conta das necessidades teóricas reveladas por debates atuais, 
interessados politicamente em sua própria localização.

Para falar sobre alguns trabalhos concluídos ou em andamento, partimos de um exemplo recente. Em outubro de 2018 começou a se consolidar uma ampla parceria em torno do projeto de um grupo de pesquisa pensado, sonhado e acolhido coletivamente por professoras e estudantes de diversas universidades. A ideia era criar um espaço de trocas de saberes, fossem eles acadêmicos ou da cultura histórica, de compartilhamento de leituras, produções e experiências, mas também um lugar de escuta ${ }^{1}$ e de acolhimento, reunindo interesses de pesquisa. Partindo de um recorte transtemporal, o grupo busca apoio no compartilhamento de experiências, de pesquisas e abordagens teóricas em investigações que tratam de mulheres, ou da população LGBTQI+, em situações consideradas periféricas, com destaque especial para os diversos relevos sociais dos sertões brasileiros, de Norte a Sul do país, sem deixar de lado periferias urbanas e a própria noção do "ser periférico" (VEIGA, 2018).

Parcerias e ações acadêmicas duradouras começaram a surgir, e um dos resultados disso é a organização do dossiê "Mulheres, Gênero e Sertanidades", publicado pela Sæculum - Revista de História, que teve a seguinte chamada:

Compreendendo sertões como um conceito amplo, referente a territórios e práticas culturais distanciados dos centros de poder e do litoral, situados no que podemos chamar de Brasil profundo (ou outras profundezas latino-americanas), propomos um número temático para a Saeculum - Revista de História, agregando estudos que problematizem sujeitos em situação de margem. História das mulheres, gênero, queer, masculinidades, interseccionalidade, (de)colonialidade, territorialidade são conceitos-chave para a historiografia que se dedica a esses e essas protagonistas - não mais objetos - da história. A proposta parte de uma perspectiva transtemporal, guiada pelo eixo das territorialidades sertanejas e das sertanidades, tratadas de modo abrangente e acolhedor, prezando a consciência da abertura de um lugar de fala e de visibilidade para essAS/es sujeitAS/os. Artigos que abordem imagens, literatura e representações sertanejas são igualmente bem vindos, na ampliação dos interesses diversos sobre as inúmeras possibilidades historiográficas que esse vasto lugar de margem oferece. Os sertões, distantes da ideia restrita de regiões semiáridas, apenas, vivem e florescem por todo o Brasil; suas práticas, memórias e histórias merecem ser (re)conhecidas.

As palavras-chave Mulheres, Gênero, Sertanidadades, Interseccionalidades e Memórias deram o mote daquilo que se pretendia discutir no dossiê. As perspectivas da teoria decolonial e do conceito de interseccionalidade permitem elaborar reflexões a respeito de sujeitas/os situadas/os, pessoas muitas vezes "racializadas" ou tomadas como hierarquicamente inferiores na sociedade brasileira, no sul do sul global. ${ }^{2}$ Essa ideia é revertida e positivada, tomando o norte do Brasil como nosso norte, quando as pesquisas e produções acadêmicas sinalizam e privilegiam seu protagonismo, mais do que qualquer tipo de discurso de vitimização historicamente construído.

Um dos primeiros estudos que trata do conceito de sertanidades, embora não dialoge com gênero, é o trabalho Ser-tão baiano: o lugar da sertanidade na configuração da identidade baiana, de Cláudia Vasconcelos (2011). A pesquisa tratou de investigar como e em que sentido o discurso hegemônico da baianidade, centrado na cidade de Salvador e seu Recôncavo, se afirmou como única referência identitária para os baianos e não-baianos, negando a existência de "outras bahias", a exemplo da presença de uma

\footnotetext{
${ }^{1}$ Amanda Paulo Alves de Oliveira (PIBIC/História da UFPB) foi quem propôs a ProjetAH como "lugar de escuta", em contraposição ao já bastante debatido "lugar de fala" sistematizado por Djamila Ribeiro (2017). Assumimos coletivamente esse lugar para o grupo de pesquisa.

2 Cf. Veiga, no prelo.
} 
existência rural/sertaneja nesse estado.

Ana Maria Veiga $(2018 ; 2019)$ tem trabalhado conceitos interligados que se referem a sujeitos/as localizados/as, que a autora ressignifica nos termos "ser" periférico, sujeitos Outros ou subjetividades Outras da história, sujeitos em situação de margem, acionando para isso teorias em situação de margem, teorias Outras da história. Lançando às protagonistas de suas pesquisas uma proposta de acolhimento, de lugares de escuta, onde elas possam se dizer. É o que está em andamento no projeto audiovisual que coordena, o Fala sertaneja (!), em execução desde outubro de 2018, coletando memórias diversas que fazem emergir uma perspectiva teórico-metodológica do "lá" e do "cá", nos contrastes que observamos em migrações e deslocamentos diversos de mulheres sertanejas, que saem de seus lugares de origem rumo a centros maiores, em busca de conhecimento e de trabalho, proporcionados pelas universidades do nordeste brasileiro. ${ }^{3}$

No sertão baiano, encontramos a preciosa história de Dona Farailda, uma casamenteira da pequena cidade de Serrolândia, que teve a trajetória de vida investigada por Vânia Vasconcelos (2017) no livro "É um romance minha vida". Este talvez seja um dos mais emblemáticos exemplos da riqueza dos estudos sobre mulheres sertanejas, pessoas comuns, mas que se destacam de alguma forma por suas práticas e modos de vida. Crenças e visões próprias de mundo fazem de Dona Farailda quase que um(a) Menocchio(a) do sertão baiano. No lugar de documentos da inquisição, como é o caso do moleiro apresentado por Carlo Ginzburg, ainda nos anos 1970, Vânia Vasconcelos se depara com o documento vivo das palavras que externaram as memórias da "casamenteira" e das pessoas de seu convívio.

Narrativas historiográficas se multiplicam. Outras tantas mulheres são colocadas em cena na investigação histórica, como as que lutaram para estudar tardiamente na educação de adultos em Januária, norte de Minas Gerais, que aparecem no trabalho de Leila de Souza Almeida (2015), ou as que se dedicam à dança do congado, também no sertão mineiro, trabalhadas por Fernanda Naves e Cairo Katrib (2015). Os dois textos mencionados fazem parte da coletânea organizada por Cláudia Maia e Vera Puga (2015), História das mulheres e do gênero em Minas Gerais. De Cláudia Maia temos ainda a obra $A$ invenção da solteirona, de 2011, que se tornou referência para os estudos de gênero e que pode ser igualmente tomada para se pensar sobre mulheres sertanejas, além de outros textos sobre violência. ${ }^{4}$

Diversos trabalhos contribuem nesse sentido, enfrentando também as representações de sertanejas e interioranas. É o caso do estudo de Caroline de Araújo Lima (2018), cuja pesquisa está embasada sobre as imagens construídas das mulheres que atuaram no cangaço, problematizando a oposição que faziam aos corpos dóceis e "femininos" prescritos às mulheres pelo ditame de padrões sociais com base no binarismo homem-mulher, que qualifica as mulheres que atuaram no cangaço na categoria "homem". O cinema e as fotografias das cangaceiras são fontes privilegiadas nessa pesquisa.

Tânia Mara Pereira Vasconcelos $(2014 ; 2018)$ mergulha na riqueza de fontes documentais ainda pouco exploradas para tratar de gênero e da história das mulheres. Nos arquivos, como os judiciários, em pequenas cidades do interior da Bahia, a historiadora encontra a "carne" empoeirada que alimenta seus trabalhos analíticos,

\footnotetext{
${ }^{3}$ A principal universidade abordada na primeira etapa do trabalho é a Universidade Federal da Paraíba, onde Ana Maria Veiga é professora.

${ }^{4}$ Cf. Maia, 2018.
} 
sejam sobre crimes de sedução de jovens mulheres cuja honra familiar precisava ser reparada ou sobre discursos impositivos que vão construindo imagens adequadas e inadequadas de mulheres sertanejas.

Susel Oliveira da Rosa (2015) publicou sobre as mulheres paraibanas na resistência à ditadura, ao latifúndio e à misoginia. Para a autora, as trabalhadoras rurais, agrupadas ou não em movimentos sociais, lidavam diariamente com ameaças ao seu trabalho e às suas vidas, no confronto com a opressão de Estado e no estado da Paraíba, no que denomina ditadura latifundiária-militar.

Certamente, uma história das sensibilidades ${ }^{5}$ é acionada ao lidarmos com esses sujeitos que buscamos compreender. As mulheres sertanejas, como exemplo, estiveram e continuam muitas vezes à frente de suas famílias na lida com a precariedade e na luta pela existência cotidiana. E o nordeste brasileiro, em seu interior, aparece como palco dessas histórias. Podemos mencionar os casos do Movimento de Mulheres Trabalhadoras (MMT) e do Movimento de Mulheres do Brejo paraibano (MMB), que entraram em atividade nos primeiros anos 1980, sendo que o MMB continua atuando até hoje. Os movimentos foram estudados na dissertação de Vera Lúcia de Mendonça Silva (1995), também por Emmy Lyra Duarte $(2014,2015)$ e, mais recentemente, por Laianny Cordeiro Silva de Souza (2014 e em sua dissertação de mestrado de 2019).

Alômia Abrantes da Silva (2006), na tese Paraíba, mulher-macho: tessituras de gênero, (desa)fios da história, e em outros escritos ${ }^{6}$, situa a construção de estereótipos nos discursos sobre as mulheres paraibanas e na constituição de sua identidade regional, ainda sob a força fálica do cabra-macho do qual essas mulheres são levadas discursivamente a assumir a figura. ${ }^{7}$

Esses trabalhos, de alguma forma, além de trazerem inovações teóricas, se constituem em uma nova perspectiva metodológica, pela própria forma como dialoga com suas fontes e personagens; estas são ouvidas dentro de uma de um novo "lugar de escuta".

Além delas, outras historiadoras já começam a encarar a tarefa de trazer à tona histórias locais e regionais que se aglutinam no sentido de moldar uma outra face da historiografia brasileira, que fazem dos sertões e da teoria feminista seu ponto de partida - com sorte, também de chegada - pois, além disso, essa é uma história, ao mesmo tempo cultural e social, preocupada com a teoria, mas também com o ensino e com modos de devolução da pesquisa para esses/as sujeitos/as.

Não pensamos as mulheres sertanejas como um grupo coeso, unitário, evitando cair em uma "armadilha essencialista". Identidades regionalistas são um tanto perigosas e não representam os sujeitos e sujeitas em seus cotidianos, são criações a partir de relações de poder em disputas territoriais imaginarias, marcadas por referenciais colonialistas que determinam os binarismos centro/periferia. A proposta é mostrar a diversidade de existência dessas/es sujeitas/os historicamente invisibilizadas e/ou vistas a partir de olhares que lhes negaram o protagonismo, a invenção da subjetividade (Rago, 2013), a "tomada nas mãos" da própria existência.

Mesmo a possibilidade da realização do dossiê "Mulheres, gênero e sertanidades" sinaliza a constituição e o fortalecimento de um campo de pesquisas que vai além dos tradicionais estudos e visões sobre sertão/sertões, compreendidos aqui em seu distanciamento dos grandes centros, analisados por meio de abordagens

\footnotetext{
${ }^{5}$ Cf. Arfuch, 2016.

${ }^{6}$ Cf. Abrantes da Silva, 2006.

7 Sob essa perspectiva, ver também os trabalhos de Durval Muniz de Albuquerque Júnior, 2011, 2013, 2016.
} 
específicas, como gênero e história das mulheres. É esse o princípio que dá origem ao Grupo de Pesquisa ProjetAH - História das Mulheres, Gênero, Imagens, Sertões, que já rende outros tipos de encontros e de produção de conhecimento, buscando construir um espaço que ao mesmo tempo que é acadêmico, é também afetivo.

\section{Referências}

ABRANTES DA SILVA, Alômia. Que faz da Paraíba uma "mulher macho"? Gênero, política e saber na construção de uma identidade regional. In: Antônio de Pádua Dias da Silva. (Org.). Representações de Gênero e de Sexualidades: inventários diversificados. João Pessoa: Ed. UFPB, 2006, p. 66-73.

ABRANTES DA SILVA, Alômia. Paraíba, mulher-macho: tessituras de gênero, (desa)fios da história. 252 f. Tese (Doutorado em História) Universidade Federal de Pernambuco. Recife, 2008.

ALBUQUERQUE JÚNIOR, Durval M. Nordestino, invenção do "falo": uma história do gênero masculino (1920-1940) (2a edição). 2a. ed. São Paulo: Intermeios, 2013.

ALBUQUERQUE JÚNIOR, Durval M. Vede sertão, verdes sertões: cinema, fotografia e literatura na construção de outras paisagens nordestinas. Fenix: revista de historia e estudos culturais, v. 13, p. 01-27, 2016.

ALBUQUERQUE JÚNIOR, Durval M. Preconceito Contra a Origem Geográfica e de Lugar: As Fronteiras da Discórdia. São Paulo: Cortez, 2011.

ALMEIDA, Leila de Souza. "Recebi um diploma, realizei um sonho": mulheres e educação de adultos em Januária. In: MAIA, Cláudia; PUGA, Vera Lúcia (Org.). História das mulheres e do Gênero em Minas Gerais. Florianópolis: Ed. Mulheres, 2015, p. 369394.

ARFUCH, Leonor. El "giro afectivo". Emociones, subjetividad y política. DeSignis. Argentina. N.24, enero-julio 2016, p. 245-254. Disponível em http://www.designisfels.net/revista/emociones-en-la-nueva-esfera-publica.

CRENSHAW, Kimberlé. Documento para o encontro de especialistas em aspectos da discriminação racial relativos ao gênero. Revista Estudos Feministas, v.10, n.1, 2002, p. 171-188.

DUARTE, Emmy Lyra. Movimento de Mulheres Trabalhadoras da Paraíba (MMT/PB): mobilização social, trabalho e relações de gênero. Dissertação de Mestrado em Geografia. João Pessoa: UFPB, 2014.

DUARTE, Emmy Lyra; GARCÍA, María Franco. Movimentos de Mulheres Trabalhadoras no estado da Paraíba: gênero e autonomia. Interespaço - revista de geografia e interdisciplinaridade, v.1, n.3, São Luís, 2015, p. 132-151.

KATRIB, Cairo M. I.; NAVES, Fernanda D. O Congado me chamou: trajetórias e memórias das mulheres congadeiras de Ituiutaba-MG. In: MAIA, Cláudia; PUGA, Vera Lúcia (Org.). História das mulheres e do Gênero em Minas Gerais. Florianópolis: Ed. Mulheres, 2015, p. 281-304.

LIMA, Caroline de A. Cangaceiras em um click: imagens e representações do feminino no cangaço. Ponta de Lança (UFS), v. 12, p. 107-123, 2018. 
LUGONES, María. Rumo a um feminismo descolonial. Revista Estudos Feministas, v.22, n.3, 2014. p. 935-952.

LUGONES, María. Colonialidad y género. Tabula Rasa. Bogotá - Colombia, n.9, p. 73101, julio-diciembre, 2008.

MAIA, Cláudia. Vidas que não importam: violência contra mulheres e biopolítica no norte de Minas, os efeitos da lei 11.340/2006. Labrys (edição em português), v. 30, p. online, 2017.

MAIA, Cláudia. A invenção da solteirona: Conjugalidade moderna e terror moral. Minas Gerais (1890-1948). Florianópolis: Ed. Mulheres, 2011.

MAIA, Cláudia; PUGA, Vera Lúcia (Org.). História das mulheres e do Gênero em Minas Gerais. Florianópolis: Ed. Mulheres, 2015.

QUIJANO, Aníbal (2000). Colonialidad del poder y clasificación social. Journal of worldsystems research, v. 11, n. 2, p. 342-386.

RAGO, Margareth. A aventura de contar-se: feminismos, escrita de si e invenções da subjetividade. Campinas: Editora da Unicamp, 2013.

ROSA, Susel O. Mulheres versus Ditadura, Latifúndio e Misoginia na Paraíba. Revista Estudos de Sociologia. Araraquara - SP, v.20, n.39, p. 309-324, jul./dez. 2015.

VASCONCELOS, Cláudia Pereira. Ser-Tão baiano: o lugar da sertanidade na configuração da identidade baiana. Salvador: EDUFBA, 2011.

VASCONCELOS. Tânia M. P. "Moça virgem/mulher honesta" versus "prostituta": A importância da virgindade feminina e a centralidade do corpo na construção dos binarismos de gênero em processos. Revista Feminismos, v. 6, p. 119-131, 2018.

VASCONCELOS. Tânia M. P. As filhas da mãe: representações do feminino em processos judiciais por crimes de sedução e estupro em Jacobina - Bahia (1940-1960). Diálogo (UNILASALLE), v. 1, p. 91-105, 2014.

VASCONCELOS. Vânia N. P. "É um romance minha vida": Dona Farailda, uma casamenteira no sertão baiano. Salvador: EdUFBA, 2017.

VASCONCELOS. Vânia N. P. "Nunca tomei nome de rapariga de ninguém": gênero, memória e construção de si de Dona Farailda, uma "casamenteira" do sertão baiano. Revista Feminismos, v. 1, p. 76-97, 2013.

VEIGA, Ana M. Quando Clio é preta, pobre, periférica: relocalizando a teoria da história. Conferência de abertura. Fórum de Teoria e História da Historiografia - edição Natal, UFRN, 03/12/2019.

VEIGA, Ana M. Teorias de(s)coloniais e interseccionalidades na pesquisa e no ensino de história. Projeto de pesquisa em execução no DH e no PPGH da Universidade Federal da Paraíba. João Pessoa: UFPB, maio de 2018.

VEIGA, Ana M. Uma virada epistêmica feminista (negra): conceitos e debates. Tempo e Argumento, vol.12, n.29, Florianópolis, UDESC. No prelo. 


\section{Notas de autoria}

Ana Maria Veiga é professora do curso de História e do Programa de Pós-Graduação em História da Universidade Federal da Paraíba, com pós-doutorado Interdisciplinar em Ciências Humanas pela Universidade Federal de Santa Catarina. É editora das revistas Sæculum e Estudos Feministas e líder do grupo ProjetAH: História das mulheres, Gênero, Imagens, Sertões. E-mail: anaveiga.ufpb@gmail.com.

Vânia Nara Pereira Vasconcelos é professora Adjunta da UNEB na graduação e no Programa de Pós-Graduação em História Regional e Local. Doutora em História pela UFF, com período sanduíche na Universitat Rovira i Virgili (Espanha). Desenvolve pesquisas sobre gênero, sexualidades, feminismos, mulheres e biografia, tendo publicado o livro "É um romance minha vida": D. Farailda - uma "casamenteira" no sertão baiano. Realiza pós-doutorado no Centro de Estudos Sociais, na Universidade de Coimbra. E-mail: vaniauneb5@gmail.com.

\section{Como citar esse artigo de acordo com as normas da revista}

VEIGA, Ana Maria e VASCONCELOS, Vânia N. P. Lugares de escuta e de acolhimento nas pesquisas sobre sertanidades. Sæculum - Revista de História, v. 24, n. 41, p. 196203, 2019.

\section{Contribuição de autoria}

Elaboração e contribuição coletiva.

\section{Consentimento de uso de imagem}

Não se aplica.

\section{Aprovação de comitê de ética em pesquisa}

Não se aplica.

\section{Licença de uso}

Este artigo está licenciado sob a Licença Creative Commons CC-BY. Com essa licença você pode compartilhar, adaptar, criar para qualquer fim, desde que atribua a autoria da obra.

\section{Histórico}

Recebido em 09/12/2019.

Aprovado em 11/12/2019. 